\title{
A COMPREHENSIVE THERMAL-HYDRAULIC MODEL OF AN OPEN-CYCLE GAS CORE NUCLEAR ROCKET
}

\author{
David I. Poston and Terry Kammash \\ Department of Nuclear Engineering \\ University of Michigan \\ Ann Arbor, MI 48109
}

(313) 747-0900

\begin{abstract}
$\underline{\text { Abstract }}$
A thermal-hydraulic model of an open-cycle gas core nuclear rocket is developed. The two-dimensional NavierStokes equations, the energy equation, and the species diffusion equation are solved for high temperature twospecies gas flow. A description of the model and the method of solution is presented, as well as the results for a cylindrical gas core reactor design. The results provide valuable insight into the fluid flow and species mixing within an open-cycle gas core nuclear rocket.
\end{abstract}

\section{INTRODUCTION}

In the Gas Core Nuclear Rocket (GCR) a fissioning uranium plasma heats (primarily by radiation) a hydrogen propellant, which is exhausted through a choked nozzle. In the open-cycle GCR there is no physical barrier between the fuel and propellant, thus the flow field must be constructed in a manner which minimizes fuel/propellant mixing. An open-cycle gas core nuclear rocket has the potential to deliver astounding rocket performance. Poston and Kammash (1992) found that if the fuel and propellant can be prevented from mixing, a $3000 \mathrm{MW}$ reactor can produce a specific impulse of $3160 \mathrm{~s}$ with a thrust of $125 \mathrm{kN}$. However, the open-cycle GCR receives little attention because of many unanswered questions. This model was created in order to address many of these questions: most notably fuel containment, stability, and neutron criticality considerations.

A computer code has been written which solves the Navier-Stokes, energy, and species diffusion equations as a function of design and operational parameters. The fuel (uranium) and propellant (hydrogen) enter the reactor with a constant mass flow rate; the propellant surrounds the fuel in the shape of a cylindrical annulus. The propellant enters the reactor with a user-specified velocity profile, including both inlet and wall flow. If the maximum wall heat flux is reached, the propellant flow through the wall is increased to provide transpiration cooling. In addition to the flow rates, the system dimensions, material limitations, power, and boundary conditions are used as code input. One of the most difficult tasks in modeling the open-cycle GCR is choosing an appropriate turbulence model. Because of this, the code offers several options for the modeling of turbulent eddy viscosity.

There are five equations to be solved at each node throughout the reactor: conservation of mass, species, axial momentum, radial momentum, and energy. To solve this set of equations, the energy and mass transfer equations are discretized by the finite volume method, and the momentum equations are discretized by finite differencing. The code uses a staggered grid approach, where temperature, axial velocity, radial velocity, pressure, and volume fraction are solved at different nodal points. An iterative solution is required since the equations are non-linear, and relaxation is used to arrive at convergence. A total of five different relaxation factors are used; these factors are varied within the code depending on how the solution is progressing.

\section{ANALYSIS}

\section{Equations}

In cylindrical geometry, the steady state conservation equations of mass, species, axial and radial momentum, and energy are (assuming azimuthal symmetry and axial external forces only):

$$
\frac{\partial}{\partial z}\left(\rho v_{z}\right)+\frac{1}{r} \frac{\partial}{\partial r}\left(r \rho v_{r}\right)=0,
$$




$$
\begin{gathered}
\frac{\partial}{\partial z}\left(\rho v_{z} y\right)+\frac{1}{r} \frac{\partial}{\partial r}\left(r \rho v_{r} y\right)=\frac{\partial}{\partial z}\left(\rho D_{1-2} \frac{\partial y}{\partial z}\right)+\frac{1}{r} \frac{\partial}{\partial r}\left(r \rho D_{1-2} \frac{\partial y}{\partial r}\right) \\
\rho v_{z} \frac{\partial v_{z}}{\partial z}+\rho v_{r} \frac{\partial v_{z}}{\partial r}=-\frac{\partial P}{\partial z}+\frac{\partial}{\partial z}\left(\mu \frac{\partial v_{z}}{\partial z}\right)+\frac{1}{r} \frac{\partial}{\partial r}\left(r \mu \frac{\partial v_{z}}{\partial r}\right)+\rho g_{z} \\
\rho v_{z} \frac{\partial v_{r}}{\partial z}+\rho v_{r} \frac{\partial v_{r}}{\partial r}=-\frac{\partial P}{\partial r}+\frac{\partial}{\partial z}\left(\mu \frac{\partial v_{r}}{\partial z}\right)+\frac{1}{r} \frac{\partial}{\partial r}\left(r \mu \frac{\partial v_{r}}{\partial r}\right), \\
\frac{\partial}{\partial z}\left(\rho v_{z} \overline{C_{p}} T\right)+\frac{1}{r} \frac{\partial}{\partial r}\left(\rho v_{r} \overline{C_{p}} T\right)+\sum_{i=1}^{2} \frac{\partial}{\partial z}\left(j_{z i} \overline{C_{p i}} T\right)+\sum_{i=1}^{2} \frac{1}{r} \frac{\partial}{\partial r}\left(j_{n} \overline{C_{p i}} T\right)=\frac{\partial}{\partial z}\left(k \frac{\partial T}{\partial z}\right)+\frac{1}{r} \frac{\partial}{\partial r}\left(r k \frac{\partial T}{\partial r}\right)+Q_{v}
\end{gathered}
$$

The volumetric power generation $Q_{V}$ is dependent on the fuel number density, which is representative of a constant neutron flux. The axial external force $g_{Z}$ is included in order to study the effects of rocket acceleration. Thermal radiation is modeled with the diffusion approximation. The thermal radiation absorption coefficients of the fuel and propellant are sufficiently high to justify the use of the diffusion method (the propellant is seeded with high $\mathrm{Z}$ particles to aid in the absorption of radiation at low temperatures). The diffusion method models radiative heat transfer in the form of conduction, with a conduction coefficient depending on $\mathrm{T}^{3}$. The total conductivity is:

$$
k=k_{c o n d}+k_{\text {rad }}=k_{c}+\frac{16 \sigma T^{3}}{3 a_{r}} .
$$

The diffusion approximation is valid in all regions except near the wall, where optical thickness is low. An absorption integral is evaluated to more accurately predict the radiative component of the wall heat flux:

$$
q_{w}=\frac{1}{r_{w}} \int_{0}^{r_{w}} r c_{w} \sigma T^{4} \exp \left\{-\int_{r}^{r_{w}} a_{p} d r^{\prime}\right\} d r .
$$

The conductivity coefficient at the wall is iterated until the diffusion solution produces a radiative wall heat flux equal to the result of the absorption integral.

\section{Boundary Conditions}

In order to improve the numerical stability of the model, a staggered grid approach is used. Because of this, boundary conditions for each of the five solution variables ( $T, V z, V r, P$ and $y)$ are not required at each boundary. At the inlet, all variables are specified: the temperature and pressure are uniform, the radial velocity is zero, and the free stream values of axial velocity and concentration are connected by either a step or a ramp function. At the core centerline, radial velocity is zero, and symmetry applies to all other variables. At the outer wall, the temperature, radial velocity, injection area, injection angle, and concentration are all specified, and a slip condition is assumed for axial velocity. A boundary condition for pressure is not required since pressure is calculated on the outer radial edge of the mesh cell. Also, a maximum heat flux is specified at the wall. If this value is exceeded, the flow from the wall is increased, thereby providing transpiration cooling. At the core exit, an extrapolation boundary condition is used for all variables, except axial velocity since it is calculated on the downstream edge of the mesh cell. An extrapolation boundary condition assumes that radial pressure variations due to nozzle convergence do not propagate back to the core exit. The only effect the nozzle has on the thermal-hydraulic solution is in the determination of the average reservoir pressure.

\section{Fluid Properties}

The mean properties of a mixture are dependent on the mole or mass fraction of the mixture. The mixture density, molecular weight, Rosseland and Planck mean absorptivities are weighted by mole fraction:

$$
\psi=x \psi_{1}+(1-x) \psi_{2}
$$

The enthalpy and specific heat are weighted by mass fraction:

$$
\psi=y \psi_{1}+(1-y) \psi_{2}
$$


The transport properties of the mixture, molecular heat conductivity and viscosity, are determined by:

$$
\psi=M\left(\frac{x M_{1}}{\psi_{1}}+\frac{(1-x) M_{2}}{\psi_{2}}\right)^{-1}
$$

The form of this mixing law is of little importance since molecular heat conduction and laminar viscous momentum transfer contribute very little to the solution.

Fluid properties were obtained from various reports. For hydrogen the specific heat and density were taken from Patch (1971), and the Rosseland and Planck mean absorptivities were taken from Patch (1969). The viscosity, molecular weight, and the binary diffusion coefficient for both hydrogen and uranium were found in Schneiderman (1965). All other uranium data is from Parks et al. (1968). The hydrogen contains .7 weight percent seed material with an absorption cross section of $5000 \mathrm{~m}^{2} / \mathrm{kg}$. This value was experimentally achieved by Williams et al. (1969).

\section{Turbulence}

Turbulence is modeled by the introduction of eddy viscosity $\varepsilon$, the turbulent transport coefficients of mass, momentum, and heat are defined as:

$$
D_{t}=D+\varepsilon \quad, \quad \mu_{t}=\mu+\rho \varepsilon \quad, \quad k_{t}=k+C_{p} \rho \varepsilon .
$$

The code offers the option of specifying a constant eddy viscosity, a constant dimensionless viscosity, or using one of the following models:

$$
\begin{gathered}
\varepsilon=\kappa r_{\text {mix }}\left(U_{2}-U_{1}\right) \\
\varepsilon=\kappa \frac{\mu}{\rho}\left(\frac{\mu_{1}}{\mu_{2}}\right)\left(\frac{M_{1}}{M_{2}}\right)\left(\operatorname{Re}_{1,0}-250\right)\left|\frac{U_{2}}{U_{1}}-1\right|^{1 / 2} .
\end{gathered}
$$

These models can be applied over the length of the entire reactor, or only as long as the fuel/propellant interface remains distinct. The first model is the standard turbulence relation for free jet mixing. The second model was developed by Ragsdale et al (1964). Experimentally obtained values of $\kappa$ and $r_{m i x}$ were found in various reports.

\section{Method of Solution}

To solve equations (1)-(5), the energy and mass transfer equations are discretized by the finite volume method, and the momentum equations are discretized by finite differencing. The code uses a staggered grid approach, where temperature and concentration are calculated at the center of each mesh, radial velocity and pressure at the outer radial edge of each mesh, and axial velocity at the downstream edge of each mesh. The equations are solved by a sparse matrix solver, which uses row and column pivoting to reduce numerical error. An iterative solution is required since the equations are non-linear, and relaxation is used to arrive at convergence. A total of five different relaxation factors are used; these factors are varied within the code depending on how the solution is progressing. If a high power solution is desired, the code steps gradually from low power to high power, and likewise for turbulence and rocket acceleration.

\section{Rocket Performance}

To calculate rocket performance the core exit region is modeled as a reservoir (the kinetic energy of the fluid is negligible) from which the propellant flows through a choked nozzle. The nozzle expansion ratio is defined by user input. Modeling the propellant flow through the nozzle is difficult since the fluid may dissociate, ionize and/or recombine. As a simple approach, the standard isentropic compressible flow equations are used, which yield $\mathrm{T}, \mathrm{P}$, and $\rho$ downstream in terms of the expansion ratio. Results show that this approach yields values of Isp $10 \%$ to $20 \%$ lower than calculated by Patch (1971), in which the flow of high temperature hydrogen through a choked nozzle is modeled much more thoroughly. The values of thrust and specific impulse quoted in this report are based on data from Patch (1971). However the effect of uranium flow on rocket performance is determined by using the isentropic compressible flow equations. The specific impulse of multi-species flow is:

$$
I_{s p}=\frac{1}{g} \frac{\sum_{i} \dot{m}_{i} v_{e q_{i}}}{\sum_{i} \dot{m}_{i}} \text {. }
$$




\section{RESULTS AND DISCUSSION}

To demonstrate the capabilities of the model, results are presented for $500 \mathrm{MW}$ open-cycle GCR design. Table 1 lists several input parameters and results for this design. This table is followed by a series of contour plots, which plot temperature, mole fraction, axial velocity, axial mass flux, radial velocity, radial mass flux, and radial diffusive mass flux as a function of axial and radial position.

TABLE 1. Input Parameters and Results for Base Case Open-Cycle GCR Design .

\begin{tabular}{|c|c|c|c|}
\hline Input Parameters & & Results & \\
\hline Reactor Power (MW) & 500 & Fuel Reservoir Temp. (K) & 34,400 \\
\hline Reactor Pressure (atm) & 1000 & Prop. Reservoir Temp. (K) & 5,611 \\
\hline Inlet Prop. Flow Rate $(\mathrm{kg} / \mathrm{s})$ & 3.0 & Specific Impulse (s) & 1,421 \\
\hline Wall Prop. Flow Rate $(\mathrm{kg} / \mathrm{s})$ & 0.0 & Thrust $(\mathrm{kN})$ & 55.7 \\
\hline Inlet Fuel Flow Rate $(\mathrm{kg} / \mathrm{s})$ & 1.0 & & \\
\hline Inlet Temperature $(\mathrm{K})$ & 2200 & Average Fuel Density $\left(\# / \mathrm{m}^{3}\right)$ & $7.08 \mathrm{E}+24$ \\
\hline Wall Temperature (K) & 2200 & Fuel Loading (kg) & 42.0 \\
\hline Core Length (m) & 2.00 & Fuel Residence Time (s) & 42.0 \\
\hline Fuel Radius at Inlet (m) & 1.20 & Prop. Loading (kg) & 49.2 \\
\hline Buffer Zone Outer Rad. (m) & 1.35 & Prop. Residence Time (s) & 16.4 \\
\hline Outer Wall Radius (m) & 1.50 & & \\
\hline Turbulence Model & none & & \\
\hline
\end{tabular}

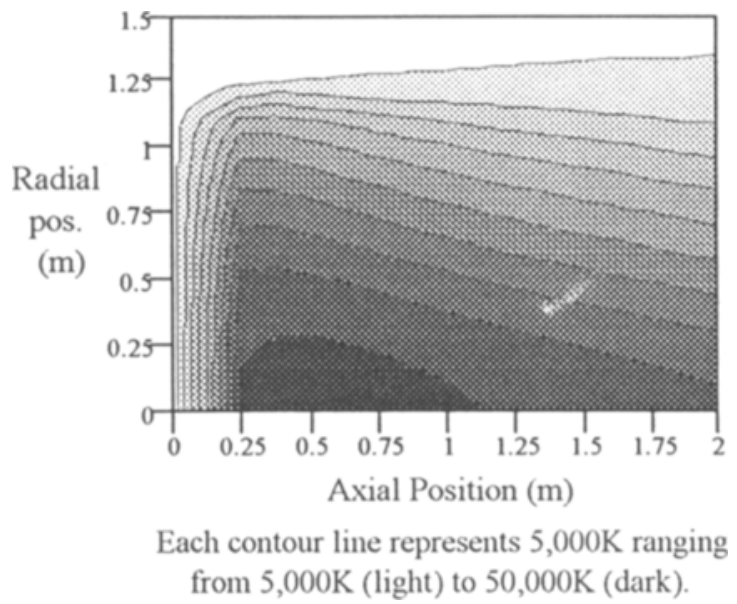

FIGURE 1. Temperature Contour Plot.

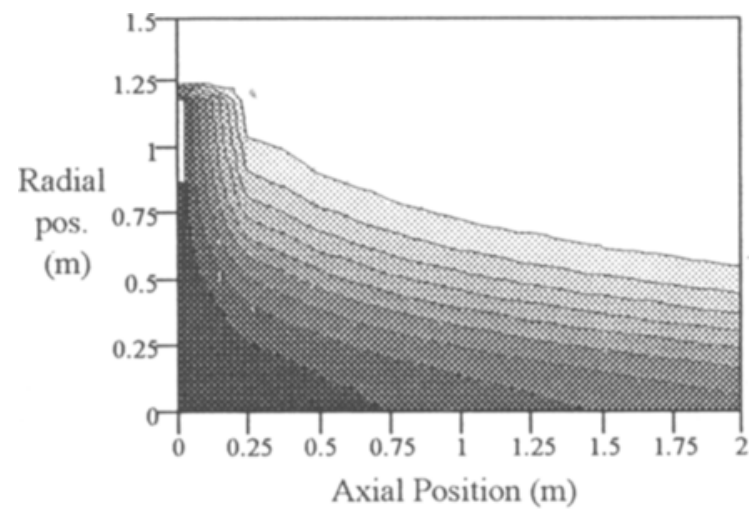

Each contour line represents 0.1 ranging from 0.1 (light) to 0.9 (dark).

FIGURE 2. Fuel Mole Fraction Contour Plot.

\section{Temperature}

As seen in Figure 1, the hottest region of the reactor is a small pocket of fuel near the inlet. The fuel temperature rises very quickly as it enters the reactor because of its low velocity and low specific heat. As the flow moves further downstream, hydrogen begins to infiltrate the core region. This causes the temperature to drop not only because the hydrogen is cool, but also because the specific heat of hydrogen is much higher than that of uranium. Only the outer contour manages to propagate toward the wall. This shows that despite the inward flow of hydrogen, the radiative heat transfer is high enough to heat fluid near the outer wall. 


\section{Fuel Mole Fraction}

The fuel concentration is shown in Figure 2. The mole fraction in the fuel region drops rapidly upon entering the reactor. This sharp drop in fuel concentration is due mainly to molecular diffusion, driven by the very steep density gradients. The more gradual decrease in concentration further downstream is a result of the inward convection of hydrogen (Figure 5) into the core. If fuel concentration was represented by mass fraction instead of mole fraction, Figure 2 would be much less dramatic because a mole fraction of .1 results in a mass fraction close to unity.

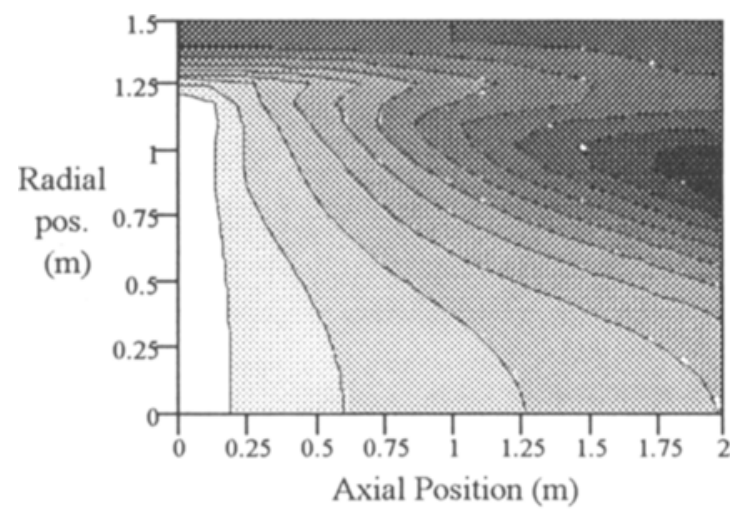

Each contour line represents $0.015 \mathrm{~m} / \mathrm{s}$ ranging from $0.015 \mathrm{~m} / \mathrm{s}$ (light) to $0.15 \mathrm{~m} / \mathrm{s}$ (dark).

FIGURE 3. Axial Velocity Contour Plot.

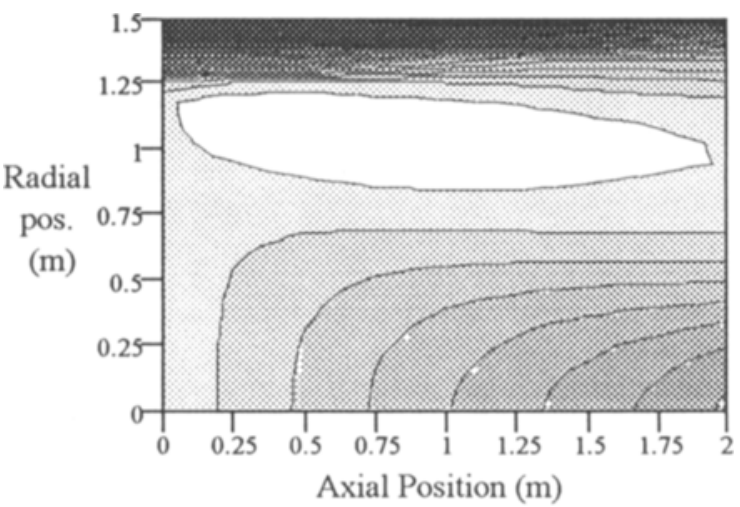

Each contour line represents $0.1 \mathrm{~kg} / \mathrm{m}^{2}$-s ranging from $0.1 \mathrm{~kg} / \mathrm{m}^{2}-\mathrm{s}$ (light) to $1.5 \mathrm{~kg} / \mathrm{m}^{2}-\mathrm{s}$ (dark).

FIGURE 4. Axial Mass Flux Contour Plot.

\section{$\underline{\text { Axial Velocity and Mass Flux }}$}

Figure 3 contains the contour plot for axial velocity. The steep velocity gradient at the inlet (which in this example has been moderated by a buffer region) begins to diffuse only a short distance into the reactor. This is a result of both the momentum exchange due to fuel/propellant mixing, and the acceleration of the fuel region due to rapid expansion. Downstream, the region which undergoes the most acceleration lies just outside the core region, and is composed mainly of hydrogen (the core region is loosely defined as anywhere where the fuel mass fraction is greater than 0.9 ). Despite the large velocity variations caused by mixing and heating, Figure 4 shows that most of the mass flux remains along the outer wall, where temperatures are cool. Figure 4 also clearly displays the acceleration of the core region near the centerline.

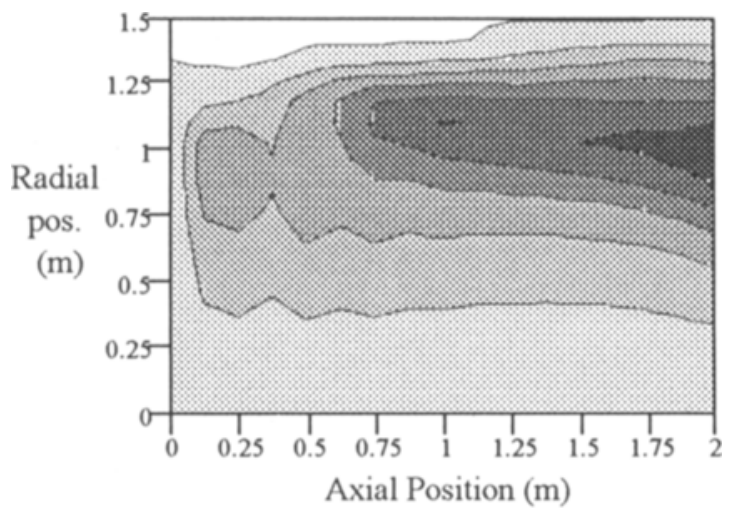

Each contour line represents $-0.005 \mathrm{~m} / \mathrm{s}$ ranging from $0.0 \mathrm{~m} / \mathrm{s}$ (light) to- $0.025 \mathrm{~m} / \mathrm{s}$ (dark).

FIGURE 5. Radial Velocity Contour Plot.

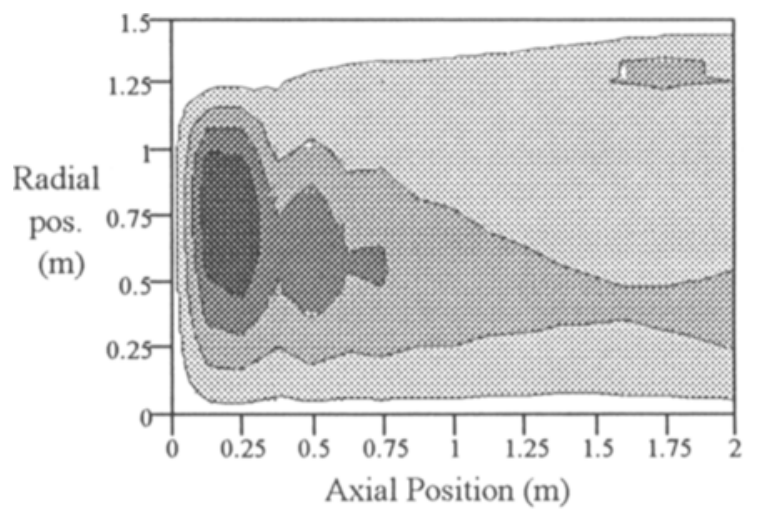

Each contour line represents $-0.025 \mathrm{~kg} / \mathrm{m}^{2}$-s ranging from $-0.025 \mathrm{~kg} / \mathrm{m}^{2}-\mathrm{s}$ (light) to $-0.1 \mathrm{~kg} / \mathrm{m}^{2}-\mathrm{s}$ (dark).

FIGURE 6. Radial Mass Flux Contour Plot. 
The radial velocity and mass flux contour plots (Figures 5 and 6) display a migration of fluid toward the center of the reactor. Figure 5 shows that there is a large influx of fluid (mostly relatively cold hydrogen) into the core region. Figure 6 seems to indicate that the only important region of convective mixing is in the fuel laden region

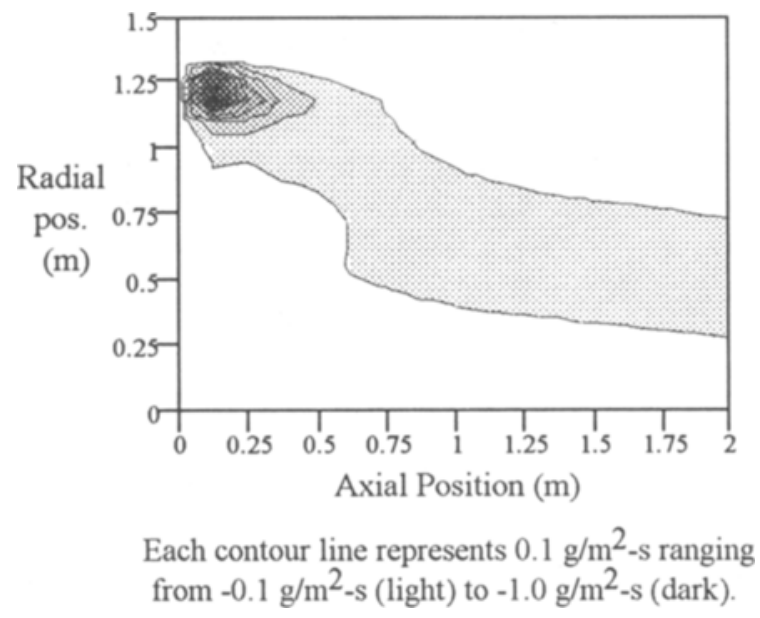

FIGURE 7. Radial Diffusive Mass Flux Contour Plot. near the reactor inlet. This is somewhat misleading, since any small movement of fuel produces a much larger mass flux than a similar movement of propellant. If particle flux was plotted, as opposed to mass flux, the plot would look more like Figure 5. In general, radial velocity and mass flux components are near or less than an order of magnitude below their axial counterparts. The discontinuities close to the inlet are the result of what could be called numerical sloshing. This sloshing can be reduced by decreasing the axial mesh spacing; however, it has been found that it does not significantly effect the downstream results. The radial diffusive flux is shown in Figure 7. There is a small region of intense mass diffusion near the entrance, where the fuel/propeliant density gradients are large. Throughout the rest of the reactor, the impact of mass diffusion, both axial and radial, is very small.

\section{Turbulence}

Two important observations can be made regarding turbulence based on results obtained thus far. The modeling of the turbulence due to coaxial jet mixing at the inlet is not as critical as initially thought. As shown above, the sharp velocity and density gradients at the inlet diffuse quickly even when only laminar flow is modeled. When turbulence is modeled only in this region, the mixing is more profuse, but the end result is similar to that of laminar flow. However, when turbulence is modeled over the entire reactor, the flow field and fuel containment of the reactor can change drastically. For a constant eddy viscosity of only $1 \mathrm{E}^{-5}$, fuel containment in the reactor drops by a factor of two. Therefore a turbulence model must be constructed which applies over the entire reactor: the two turbulence models currently used by the code apply only to jet mixing.

\section{Current and Future Work}

There are two ongoing tasks in which the model is being used. One is a parametric analysis which studies how rocket performance and fuel containment depend on design and operational parameters. The second task involves linking the model with a neutronics model. The code produces input files which can be used by two neutronics codes (TWODANT and TWODB), and in return receives flux data which is used to calculate power densities. Work will also continue on the model itself, with the emphasis being on: improving turbulence modeling, improving numerical convergence (currently the model has trouble converging for powers greater than 1,000 MW and for high levels of turbulence), and modifying the code to model a spherical geometry or the addition of an end wall.

\section{CONCLUSIONS}

A thermal-hydraulic model of an open-cycle gas core nuclear rocket is developed. The two-dimensional NavierStokes equations, the energy equation, and the species diffusion equation are solved for high temperature twospecies gas flow. Results for a $500 \mathrm{MW}$ cylindrical GCR are presented which provide valuable insight into the fluid flow and species mixing within an open-cycle gas core nuclear rocket. Future use of the model should help establish the feasibility, or lack thereof, of the open-cycle gas core nuclear rocket. 


\section{Acknowledgments}

All work was done at the University of Michigan. The work was sponsored by NASA Lewis Research Center as part of the NASA Graduate Researchers Program. The authors would like to acknowledge John Clark and Stan Borowski of NASA LeRC for their assistance.

\section{References}

Parks, D. E. et al. (1968) "Optical Constants of Uranium Plasma," NASA CR-72348, Gulf General Atomic, San Diego, CA.

Patch, R. W. (1969) "Interim Absorption Coefficients and Opacities for Hydrogen at High Pressure," NASA TMX-1902, NASA/Lewis Research Center, Cleveland, OH.

Patch, R. W. (1971) "Thermodynamic Properties and Theoretical Performance of Hydrogen to $100000 \mathrm{~K}$ and $1.01325 \times 10^{8} \mathrm{~N} / \mathrm{m}^{2}, " N A S A S P-3069$, NASA/Lewis Research Center, Cleveland, OH.

Poston, D. I., and T. Kammash (1992) "Heat Transfer Model for an Open-Cycle Gas Core Nuclear Rocket," in Proc. 9th Symposium on Space Nuclear Power Systems, CONF-920104, M. S. El-Genk and M. D. Hoover, eds., American Institute of Physics, New York, AIP Conference Proc. No. 246, 3: 1083-1088.

Ragsdale, R. G., H. Weinstein, and C. D. Lanzo (1964) "Correlation of a Turbulent Air-Bromine Coaxial-Flow Experiment," NASA TND-2121, NASA/Lewis Research Center, Cleveland, $\mathrm{OH}$.

Schneiderman, S. B. (1965) "Theoretical Viscosities and Diffusivities in High-Temperature Mixtures of Hydrogen and Uranium," NASA CR-213, United Aircraft Corporation, East Hartford, CT.

Williams, J. R., J. D. Clement, A. S. Shenoy, and W. L. Partain (1969) "The Attenuation of Radiant Energy in Hot Seeded Hydrogen," Quarterly Status Report 2, Georgia Institute of Technology, Atlanta, GA.

Nomenclature

\section{English}

$\begin{array}{ll}\mathrm{a}_{\mathrm{p}}: & \text { Planck mean abs. }(1 / \mathrm{m}) \\ \mathrm{a}_{\mathrm{r}}: & \text { Rosseland mean abs. }(1 / \mathrm{m}) \\ \mathrm{C}_{\mathrm{p}}: & \text { Specific heat }(\mathrm{J} / \mathrm{kg} \cdot \mathrm{K}) \\ \mathrm{D}_{12}: & \text { Binary diff. coef. }\left(\mathrm{m}^{2} / \mathrm{s}\right) \\ \mathrm{g}: & \text { Acceleration }\left(\mathrm{m} / \mathrm{s}^{2}\right) \\ \mathrm{I}_{\mathrm{sp}}: & \text { Specific impulse }(\mathrm{s}) \\ \mathrm{j}: & \text { Diffusive flux }\left(\mathrm{kg} / \mathrm{s} \cdot \mathrm{m}^{2}\right) \\ \mathrm{k}: & \text { Thermal conduct. }(\mathrm{W} / \mathrm{m} \cdot \mathrm{K}) \\ \mathrm{M}: & \text { Molecular weight } \\ \mathrm{m}: & \text { Mass flow rate }(\mathrm{kg} / \mathrm{s}) \\ \mathrm{P}: & \text { Pressure }(\mathrm{Pa})\end{array}$

q: $\quad$ Heat flux $\left(W / \mathrm{m}^{2}\right)$

$\mathrm{Q}_{\mathrm{y}}$ : Heat generation $\left(\mathrm{W} / \mathrm{m}^{3}\right)$

$\mathrm{r}: \quad$ Radial position $(\mathrm{m})$

Re: Reynolds Number

$\mathrm{T}$ : $\quad$ Temperature (K)

U: $\quad$ Free stream velocity $(\mathrm{m} / \mathrm{s})$

$\mathrm{v}$ : Local velocity $(\mathrm{m} / \mathrm{s})$

$v_{\text {eq: }}$ Equivalent velocity $(\mathrm{m} / \mathrm{s})$

$x:$ Fuel mole fraction

y: Fuel mass fraction

$\mathrm{z}$ : Axial position (m)

\section{Greek}

ع: Eddy Viscosity $\left(\mathrm{m}^{2} / \mathrm{s}\right)$

$\kappa: \quad$ Turbulence factor

$\mu: \quad$ Viscosity $(\mathrm{kg} / \mathrm{m} \cdot \mathrm{s})$

$\rho: \quad$ Density $\left(\mathrm{kg} / \mathrm{m}^{3}\right)$

$\sigma: \quad$ Stefan-Boltzmann Const.

$\psi$ : Dummy Variable

Subscript

w: Outer wall

1: Fuel

2: Propellant 